\title{
Mengolah COD Pada Limbah Laboratorium
}

\author{
Yenita Sandra Sari ${ }^{\text {a,1, }}$ \\ ${ }^{a}$ Universitas Kebangsaan \\ ${ }^{1}$ yenitasandra@gmail.com
}

ARTICLE INFO

Keywords

COD

Laboratory liquid waste

Fenton Reagent

\begin{abstract}
$A B S T R A C T$
Laboratory liquid waste is water produced from the rest of the testing activities in a laboratory that is categorized as dangerous. This waste has a distinctive characteristic that is different from the waste originating from industrial activities because it usually has a very high diversity of types of waste even though the amount of material disposed of is relatively small. Advance Oxidation Processes (AOPs) or advanced oxidation processes are an alternative method that is suitable to be used to treat laboratory waste. This study aims to obtain the optimum dose in decreasing the concentration of Chemical Oxygen Demand (COD) with the AOPs method using Fenton reagent (H2O2 and $\mathrm{FeSO} 4)$. The study used variations in COD concentrations of $10,090.09 \mathrm{mg} / \mathrm{L}, 5,009.01 \mathrm{mg} / \mathrm{L}$ and $511.71 \mathrm{mg} / \mathrm{L}$. The results showed that the optimum dose of Fenton reagent was 1: 300 with the efficiency of decreasing COD levels for COD concentrations of $10,090.09 \mathrm{mg} / \mathrm{L}$ by $21.43 \%$, for COD concentrations of $5,009.01 \mathrm{mg} / \mathrm{L}$ of $46.76 \%$ and for COD concentrations of $511,71 \mathrm{mg} / \mathrm{L}$ of $83.10 \%$.
\end{abstract}

\section{PENDAHULUAN}

Limbah cair laboratorium adalah air yang dihasilkan sisa dari kegiatan pengujian di laboratorium yang dikategorikan berbahaya. Air limbah cair laboratorium mengandung zat-zat yang berbahaya dan bisa mencemari lingkungan bila tidak diolah terlebih dahulu. Limbah cair laboratorium terdiri dari bahan kimia senyawa organik dan anorganik dengan konsentrasi dan kuantitas tertentu. Tingkat bahaya keracunan yang ditimbulkan oleh limbah cair laboratorium tergantung pada jenis dan karakteristik limbah tersebut.

Pencemaran oleh air limbah laboratorium merupakan salah satu masalah lingkungan yang perlu diperhatikan dengan seksama sebelum menimbulkan akibat-akibat yang lebih serius. Kadar yang umum diuji dalam limbah cair laboratorium adalah kadar COD (Chemical Oxygen Demand). COD merupakan salah satu parameter indikator penting untuk mengetahui pencemaran di dalam air yang disebabkan oleh limbah organik, secara umum konsentrasi COD yang tinggi dalam air menunjukkan banyaknya cemaran yang bersifat kimia yang terkandung dalam air. Besarnya nilai COD sebanding dengan besarnya nilai cemaran yang ada dalam air.

\subsection{Chemical Oxygen Demand (COD)}

Untuk menyatakan kualitas air dibutuhkan beberapa parameter yang terkait. Salah satu diantaranya adalah Chemical Okxygen Demand (COD) yang didefinisikan sebagai jumlah oksigen $\left(\mathrm{mg} \mathrm{O}_{2}\right)$ yang dibutuhkan untuk mengoksidasi zat-zat organik yang terdapat di dalam sampel air atau banyaknya oksigen yang dibutuhkan untuk mengoksidasi zat organik menjadi $\mathrm{CO}_{2}$ dan $\mathrm{H}_{2} \mathrm{O}$. Pada reaksi ini hampir semua zat yaitu sekitar $85 \%$ dapat teroksidasi menjadi $\mathrm{CO}_{2}$ dan $\mathrm{H}_{2} \mathrm{O}$ dalam suasana asam.

Angka COD merupakan ukuran bagi pencemaran air oleh zat-zat organik yang secara alamiah dapat teroksidasi melalui proses mikrobiologis dan mengakibatkan berkurangnya oksigen terlarut di dalam air.

COD adalah banyaknya oksigen yang dibutuhkan untuk mengoksidasi senyawa organik dalam air, sehingga parameter COD mencerminkan banyaknya senyawa organik yang dioksidasi secara 
kimia. Pengujian COD digunakan untuk menghitung kadar bahan organik yang dapat dioksidasi dengan cara menggunakan bahan kimia oksidator kuat dalam media asam.

\subsection{Advance Oxidation Processes (AOPs)}

Advance Oxidation Processes (AOPs) atau proses oksidasi lanjutan merupakan suatu metode alternatif yang sesuai digunakan untuk mengolah limbah laboratorium.

Prosedur AOPs ini sangat berguna untuk membersihkan bahan-bahan biologis beracun seperti aromatik, pestisida, konstituen minyak, dan senyawa organik yang mudah menguap dalam air limbah. Bahan kontaminan dikonversi untuk sebagian besar menjadi senyawa anorganik stabil seperti karbon dioksida dan garam yang akan mengalami mineralisasi. Tujuan dari pemurnian air limbah dengan cara AOPs adalah pengurangan kontaminan kimia dan toksisitas sedemikian rupa sehingga air limbah dapat dibersihkan kembali untuk digunakan lagi atau setidaknya menjadi pengolahan kovensiolnal.

\section{Proses homogen dengan menggunakan radiasi UV}

AOPs homogen menggunakan radiasi UV umumnya digunakan untuk degradasi senyawa yang menyerap radiasi UV dalam kisaran yang sesuai spektrum. Senyawa yang menyerap sinar UV pada panjang gelombang yng rendah baik untuk foto degradasi. Jenis-jenisnya antara lain:

a. Ozon dan radiasi ultraviolet $\left(\mathrm{O}_{3} / \mathrm{UV}\right)$

Proses oksidasi lanjutan menggunakan ozon dan radiasi UV dimulai dari fotolisis ozon, yang menghasilkan pembentukan radikal hidroksil seperti yang ditujukan dalam reaksi berikut:

$$
\begin{aligned}
& \mathrm{hv} \\
& \mathrm{H}_{2} \mathrm{O}+\mathrm{O}_{3} \rightarrow 2 \mathrm{OH}^{*}+\mathrm{O}_{2} \\
& 2 \mathrm{OH}^{*} \rightarrow \mathrm{H}_{2} \mathrm{O}_{2}
\end{aligned}
$$

Teknologi AOPs dengan kombinasi ozon dan sinar ultraviolet ini memiliki bebrapa keunggulan dalam pengolahan limbah diantaranya:

1. Areal instalasi pengolahan air limbah yang dibutuhkan tidak luas.

2. Waktu pengolahan cepat.

3. Penguraian senyawa organic efektif.

4. Keluaran limbah yang berupa lumpur sedikit.

b. Hidrogen perokida dan radiasi ultraviolet $\left(\mathrm{H}_{2} \mathrm{O}_{2} / \mathrm{UV}\right)$

Proses oksidasi ini membutuhkan pembentukan radikal hidroksil yang dihasilkan oleh fotolisis $\mathrm{H}_{2} \mathrm{O}_{2}$ dan reaksi propagasi yang sesuai. Ditunjukan dalam reaksi berikut:

$$
\begin{gathered}
\mathrm{hv} \\
\mathrm{H}_{2} \mathrm{O}_{2} \rightarrow 2 \mathrm{OH}^{*}
\end{gathered}
$$

c. Ozon, hidrogen peroksida dan ultraviolet $\left(\mathrm{O}_{3} / \mathrm{H}_{2} \mathrm{O}_{2} / \mathrm{UV}\right)$

Hidrogen peroksida yang digunakan dalam proses $\mathrm{O}_{3} / \mathrm{UV}$ mempercepat penguraian ozon dan meningkatkan generasi $\bullet \mathrm{OH}$ radikal. Proses ini merupakan hasil dari kombinasi dari sistem 2 biner $\mathrm{O}_{3} / \mathrm{UV}$ dan $\mathrm{O}_{3} / \mathrm{H}_{2} \mathrm{O}_{2}$.

$$
\begin{gathered}
\mathrm{hv} \\
2 \mathrm{O}_{3}+\mathrm{H}_{2} \mathrm{O}_{2} \rightarrow 2 \mathrm{OH}^{*}+3 \mathrm{O}_{2}
\end{gathered}
$$




\section{d. Foto Fenton $\left(\mathrm{Fe}^{2+} / \mathrm{H}_{2} \mathrm{O}_{2} / \mathrm{UV}\right)$}

Lebih dari satu abad lalu, HJ Fenton menggambarkan oksidasi kekuatan hidrogen peroksida pada beberapa molekul organik dimana radikal $\mathrm{OH}^{*}$ yang dihasilkan dari hidrogen peroksida dibawah penambahan Fe(II) sebagai katalis. Kemudian, ditemukan bahwa hal ini disebabkan karena generasi radikal hidroksil, ditunjuka dalam reaksi:

$$
\mathrm{Fe}^{2+}+\mathrm{H}_{2} \mathrm{O}_{2} \rightarrow \mathrm{Fe}^{3+}+\mathrm{OH}^{-}+\mathrm{OH}^{*}
$$

Karena kesederhanaannya reaksi fenton adalah proses yang paling sering digunakan untuk menghilangkan senyawa yang sukar. Reansinya antara lain:

$$
\begin{aligned}
& \mathrm{Fe}^{2+}+\mathrm{H}_{2} \mathrm{O}_{2} \rightarrow \mathrm{Fe}^{3+}+\mathrm{OH}^{-}+\mathrm{OH}^{*} \\
& \text { hv } \\
& \mathrm{Fe}^{3+}+\mathrm{H}_{2} \mathrm{O} \rightarrow \mathrm{Fe}^{2+}+\mathrm{H}^{+}+\mathrm{OH}^{*} \\
& \mathrm{hv} \\
& \mathrm{H}_{2} \mathrm{O}_{2} \rightarrow 2 \mathrm{OH}^{*}
\end{aligned}
$$

2. Proses homogen menggunakan energi ultrasonic

a. Hidrogen peroksida dan ultrasonic

Dengan menggabungkan ultrasonic dan $\mathrm{H}_{2} \mathrm{O}_{2}$ hal tersebut mencapai pembentukan radikal bebas dalam fase gas gelembung. Reaksi yang dihasilkan adalag sebagai berikut:

$$
\begin{aligned}
& \mathrm{H}_{2} \mathrm{O}_{2} \rightarrow \mathrm{OH}^{*}+\mathrm{OH}^{*} \\
& \mathrm{H}_{2} \mathrm{O}_{2}+\mathrm{O} 2 \rightarrow \mathrm{O}_{2} * \mathrm{H}+\mathrm{O}_{2} * \mathrm{H} \\
& \mathrm{H}_{2} \mathrm{O}_{2}+\mathrm{OH}^{*} \rightarrow \mathrm{O}_{2} * \mathrm{H}+\mathrm{H}_{2} \mathrm{O}
\end{aligned}
$$

\section{Proses homogen menggunakan energi listrik}

Jenis proses didasarkan penggunaan listrik untuk memecah molekul dan senyawa untuk didegradasi. Intervensu radikak hidroksil menghasilkan transfer elektron. Metode ini memiliki beberapa keuntungan seperti peningkatan efektifits proses dan pengurangan penggunaan reagen lainnya. Selain itu, perlu dipertimbangkan biaya energi dan durasi dalam elektroda. Adapun jenisnya antara lain:

a. Oksidasi elektrokimia

b. Anodik oksidasi

c. Elekrofenton

4. Proses homogen yang tidak menggunakan energi

a. Ozonasi dalam media alkali

Ozon tidak stabil dalam medium berair, dekomposisi spontan oleh mekanisme kompleks yang melibatkan generasi hidroksil radikal bebas. Degradasi senyawa terjadi melalui aksi ozon itu sendiri serta melalui radikal yang dihasilkan dalam media basa. Dalam hal ini, ketika pH meningkat, tingkat produksi radikal $\mathrm{OH}^{*}$ di ozonisasi juga meningkat karena dari reaksi berikut:

$$
\begin{aligned}
& \mathrm{O} 3+\mathrm{OH}^{-} \rightarrow \mathrm{O}_{3}^{*^{-}}+\mathrm{OH}^{*} \\
& \mathrm{O}_{3}^{*-} \rightarrow \mathrm{O}_{2}+\mathrm{O}^{*-}
\end{aligned}
$$




$$
\mathrm{O}^{*^{-}}+\mathrm{H}^{+} \rightarrow \mathrm{OH}^{*}
$$

\section{b. Ozonasi dengan hidrogen peroksida}

Hidrogen peroksida dalam larutan berair adalah sebagian dipisahkan dengan anion hidroperoksida $\left(\mathrm{HO}_{2}^{-}\right)$, yang bereaksi dengan ozon menimbulkan serangkaian rantai reaksi termasuk radikal hidroksil.

$$
\begin{aligned}
& \mathrm{H}_{2} \mathrm{O}_{2}+2 \mathrm{O}_{3} \rightarrow 2 \mathrm{OH}^{*}+3 \mathrm{O}_{2} \\
& \mathrm{HO}_{2}^{-}+\mathrm{O}_{3} \rightarrow \mathrm{O}_{2} * \mathrm{H}+\mathrm{O}_{3}{ }^{*}
\end{aligned}
$$

Metode ini otomatis dapat dengan mudah bisa digunakan untuk degradasi hampir semua komponen.

\section{c. Hidrogen peroksida dan katalis $\mathrm{Fe}^{2+}$ (Fenton)}

Jenis reaksinya sangat mirip dengan yang terjadi di proses foto fenton, tetapi pada hidrogen peroksida dan katalis ini pembentukan radikal $\mathrm{OH}^{*}$ lebih rendah karena radiasi UV tidak terdapat dalam proses.

$$
\mathrm{Fe}^{2+}+\mathrm{H}_{2} \mathrm{O}_{2} \rightarrow \mathrm{Fe}^{3+}+\mathrm{OH}^{-}+\mathrm{OH}^{*}
$$

Jenis metode ini efektif diterapkan sebagai pra-perlakuan, tetapi memiliki kelemahan seperti lumpur hidroksida besi dan nilai $\mathrm{pH}$ yang rendah.

\subsection{Reagen Fenton}

Metode fenton adalah salah satu bentuk metode yang semakin banyak digunakan pada penanggulangan kontaminasi air dan tanah. Reagen fenton yang sederhana melibatkan digunakannya salah satu dari agen pengoksidasian (hidrogen peroksida) dan katalisatornya (garam besi atau oksida, biasanya besi). Sementara itu, proses foto fenton juga melibatkan penyinaran dengan cahaya matahari atau sumber cahaya buatan, dimana meningkatnya degradasi kontaminasi dengan menimbulkan reduksi dari $\mathrm{Fe}^{3+} \mathrm{ke} \mathrm{Fe}^{2+}$. Reaksi yang menghasilkan berbagai radikal bebas, dimana dapat bereaksi dengan senyawa organik berlebih. Reaksi yang melibatkan radikal hidroksil yang sangat reaktif adalah yang paling penting, dan karakteristik dari semua proses oksidasi lanjutan (AOPs).

Reaksi Fenton sekarang banyak digunakan dalam penanganan air limbah, tanah dan lumpur terkontaminasi dengan beberapa aplikasi sebagai berikut:

1. Destruksi polutan organik.

2. Penurunan sifat racun.

3. Peningkatan biodegradasi.

4. Penurunan BOD/COD.

5. Penghilangan warna dan bau.

6. Destruksi resin pada lumpur terkontaminasi radioaktif.

Kondisi $\mathrm{pH}$ optimum pereaksi fenton untuk menurunkan COD terjadi pada $\mathrm{pH}$ 3. Pada $\mathrm{pH}$ ini pembentukan radikal hidroksil maksimum sehingga dapat menurunkan COD yang tertinggi.

$$
\mathrm{H}_{2} \mathrm{O}_{2}+\mathrm{Fe}^{2+} \rightarrow \mathrm{Fe}^{3+}+\mathrm{OH}^{-}+\mathrm{OH}^{*}
$$

Semakin besar perbandingan nmol pereaksi fenton (dalam hal ini konsentrasi $\mathrm{H}_{2} \mathrm{O}_{2}$ ), maka semakin besar persen efisiensi penurunan COD sampai mencapai keadaan optimum. Setelah melewati perbandingan mmol pereaksi fenton optimal maka nilai COD akan kembali membesar. Hal ini dikarenakan kenaikan konsentrasi akan menimbulkan konsentrasi $\mathrm{OH}^{*}$ dalam pereaksi, sehingga kemampuan pereaksi fenton untuk mengoksidasi kontaminan dari sampel limbah semakin meningkat. Tetapi jika $\mathrm{OH}^{*}$ sudah jenuh untuk mengoksidasi maka pereaksi fenton akan terhitung 
sebagai polutan sehingga menyebabkan nilai COD menjadi meningkat setelah mencapai kondisi optimum (Agustina TE, 2012).

\section{METODE PENELITIAN}

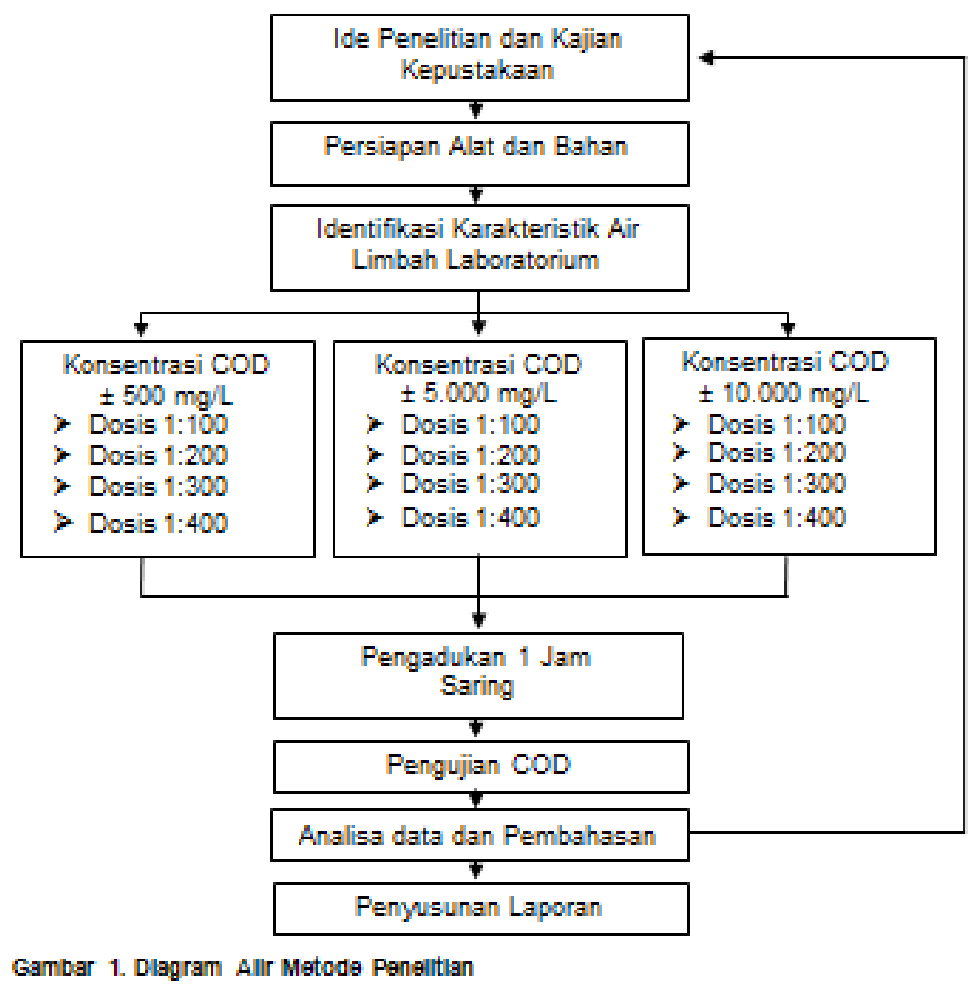

\section{Bahan-bahan yang digunakan}

1. Air bebas organik.

2. Larutan pereaksi asam sulfat. (Dari MERCK).

Ditimbang 10,12 g serbuk atau Kristal $\mathrm{Ag}_{2} \mathrm{SO}_{4}$ dilarutkan ke dalam $1000 \mathrm{~mL} \mathrm{H}_{2} \mathrm{SO}_{4}$ pekat kemudian aduk hingga larut.

3. Larutan baku $\mathrm{K}_{2} \mathrm{Cr}_{2} \mathrm{O}_{7} 0,01667 \mathrm{M}(\approx 0,1 \mathrm{~N})$ Digestion soliution. (Dari MERCK).

Ditimbang 4,903 $\mathrm{g} \mathrm{K}_{2} \mathrm{Cr}_{2} \mathrm{O}_{7}$ yang telah dikeringkan pada suhu $150^{\circ} \mathrm{C}$ selama 2 jam dilarutkan ke dalam $500 \mathrm{~mL}$ air bebas organik. Ditambahkan $167 \mathrm{~mL} \mathrm{H}_{2} \mathrm{SO}_{4}$ pekat dan 33,3 g HgSO 4 . Dilarutkan dan dinginkan pada suhu ruang dan diencerkan sampai $1000 \mathrm{~mL}$.

4. Larutan indicator Feroin. (Dari MERCK).

5. Larutan baku Ferro Ammonium Sulfat (FAS) 0,05 N. (Dari MERCK).

Ditimbang 19,6 g Fe( $\left(\mathrm{NH}_{4}\right)_{2}\left(\mathrm{SO}_{4}\right)_{2} \cdot 6 \mathrm{H}_{2} \mathrm{O}$ dalam $300 \mathrm{~mL}$ air bebas organik. Ditambahkan $20 \mathrm{~mL}$ $\mathrm{H}_{2} \mathrm{SO}_{4}$ pekat, dinginkan dan ditepatkan sampai $1000 \mathrm{~mL}$.

6. Hidrogen Peroksida $\left(\mathrm{H}_{2} \mathrm{O}_{2}\right) 20 \%$ ( Dari Brataco).

7. $\mathrm{FeSO}_{4} .7 \mathrm{H}_{2} \mathrm{O}$ (Dari MERCK).

8. $\mathrm{NaOH}$ (Dari MERCK).

9. Kertas saring kasar.

\section{Alat-alat yang digunakan}

1. Digestion Vassel (Dari Hach).

2. Pemanas dengan lubang-lubang penyangga tabung (Dari Hach).

3. Mikroburet (Dari Iwaki Pyrex).

4. Labu ukur $100 \mathrm{~mL}$ dan $1000 \mathrm{~mL}$ (Dari Iwaki Pyrex).

5. Pipet Volumetrik $5 \mathrm{~mL}, 10 \mathrm{~mL}$ dan $25 \mathrm{~mL}$ (Dari Iwaki Pyrex).

6. Pipet Ukur $5 \mathrm{~mL}, 10 \mathrm{~mL}$ dan $25 \mathrm{~mL}$ (Dari Iwaki Pyrex). 
7. Erlenmeyer $250 \mathrm{~mL}$ (Dari Iwaki Pyrex).

8. Gelas kimia $250 \mathrm{~mL}$ (Dari Iwaki Pyrex).

9. Timbangan Analitik dengan keteliian 0,1 mg (Dari Metler Toledo).

10. Magnetic Stirer (Dari Thermo Sciencetific)

11. Gelas kimia $250 \mathrm{~mL}$ (Dari Iwaki Pyrex).

12. Pipet Volumetrik $5 \mathrm{~mL}, 10 \mathrm{~mL}$ dan $25 \mathrm{~mL}$ (Dari Iwaki Pyrex).

13. Stopwatch

\section{Metode Penelitian}

Penelitian ini merupakan penelitian skala laboratorium untuk menganalisa efisiensi penurunan parameter COD pada air limbah Laboratorium dengan metode AOPs secara Batch berbasis $\mathrm{H}_{2} \mathrm{O}_{2}$ dan $\mathrm{FeSO}_{4}$.

Penelitian terdiri dari dua tahapan, yaitu: penelitian pendahuluan merupakan analisa laboratorium untuk mengetahui kosentrasi COD pada limbah laboratorium dan penelitian utama dengan tujuan yang akan dicapai yaitu dosis pereaksi Fenton yang tepat untuk setiap variasi konsentrasi skala laboratorium untuk menganalisa efisiensi penurunan parameter COD.

Data yang diperoleh disajikan dalam bentuk tabel dan grafik untuk mempermudah dalam menarik kesimpulan dan interpretasi data hasil percobaan. Secara umum, bagan air metodologi penelitian dapat dilihat pada Gambar 1. Berdasarkan Gambar 1, penelitian dimulai dengan Kajian Kepustakaan yang diperlukan untuk mendukung kajian-kajian yang ada pada penelitian ini. Kepustakaan atau literatur dapat bersumber pada: jurnal, tugas akhir, buku teks, internet dan laporan penelitian lain. Tahap persiapan dilakukan untuk menentukan teknik sampling di lokasi, persiapan alat dan bahan yang di perlukan dalam penelitian. Sampling perlu dilakukan sebelum melakukan tahap penelitian. Sampling masuk ke dalam tahap persiapan karena diperlukannya datadata primer yang bertujuan untuk mengetahui karakteristik dari air limbah tesebut. Pada penelitian ini metode pengambilan sampel yang digunakan adalah Grab sample (pengambilan sampel sesaat). Pengambilan sampel air limbah dilakukan pada influent dari Laboratorium.

Prosedur Penelitian

a. Dosis 1:100

1. Diukur $100 \mathrm{~mL}$ sampel air limbah laboratorium dengan konsentrasi COD $\pm 500 \mathrm{mg} / \mathrm{L}$, $\pm 5.000 \mathrm{mg} / \mathrm{L}$ dan $\pm 10.000 \mathrm{mg} / \mathrm{L}$ ke dalam ,masing-masing gelas kimia $250 \mathrm{~mL}$.

2. $\mathrm{pH}$ diatur menjadi 3 dengan penambahan $\mathrm{NaOH}$ atau $\mathrm{H}_{2} \mathrm{SO}_{4}$.

3. Ditambahkan $15 \mathrm{~mL}$ pereaksi Fenton 1:100.

4. Dikocok selama 1 jam.

5. Disaring untuk memisahkan endapan dengan menggunakan kertas saring dan dihitung nilai COD masing-masing larutan.

b. Dosis 1:200

1. Diukur $100 \mathrm{~mL}$ sampel air limbah laboratorium dengan konsentrasi COD $\pm 500 \mathrm{mg} / \mathrm{L}$, $\pm 5.000 \mathrm{mg} / \mathrm{L}$ dan $\pm 10.000 \mathrm{mg} / \mathrm{L}$ ke dalam ,masing-masing gelas kimia $250 \mathrm{~mL}$.

2. pH diatur menjadi 3 dengan penambahan $\mathrm{NaOH}$ atau $\mathrm{H}_{2} \mathrm{SO}_{4}$.

3. Ditambahkan $15 \mathrm{~mL}$ pereaksi Fenton 1:200.

4. Dikocok selama 1 jam.

5. Disaring untuk memisahkan endapan dengan menggunakan kertas saring dan dihitung nilai COD masing-masing larutan.

c. Dosis 1:300

1. Diukur $100 \mathrm{~mL}$ sampel air limbah laboratorium dengan konsentrasi COD $\pm 500 \mathrm{mg} / \mathrm{L}$, $\pm 5.000 \mathrm{mg} / \mathrm{L}$ dan $\pm 10.000 \mathrm{mg} / \mathrm{L}$ ke dalam ,masing-masing gelas kimia $250 \mathrm{~mL}$.

2. $\mathrm{pH}$ diatur menjadi 3 dengan penambahan $\mathrm{NaOH}$ atau $\mathrm{H}_{2} \mathrm{SO}_{4}$.

3. Ditambahkan $15 \mathrm{~mL}$ pereaksi Fenton 1:300.

4. Dikocok selama 1 jam.

5. Disaring untuk memisahkan endapan dengan menggunakan kertas saring dan dihitung nilai COD masing-masing larutan.

d. Dosis 1:400 
1. Diukur $100 \mathrm{~mL}$ sampel air limbah laboratorium dengan konsentrasi COD $\pm 500 \mathrm{mg} / \mathrm{L}$, $\pm 5.000 \mathrm{mg} / \mathrm{L}$ dan $\pm 10.000 \mathrm{mg} / \mathrm{L}$ ke dalam ,masing-masing gelas kimia $250 \mathrm{~mL}$.

2. $\mathrm{pH}$ diatur menjadi 3 dengan penambahan $\mathrm{NaOH}$ atau $\mathrm{H}_{2} \mathrm{SO}_{4}$.

3. Ditambahkan $15 \mathrm{~mL}$ pereaksi Fenton 1:400.

4. Dikocok selama 1 jam.

5. Disaring untuk memisahkan endapan dengan menggunakan kertas saring dan dihitung nilai COD masing-masing larutan.

\section{HASIL DAN PEMBAHASAN}

Penelitian awal dilakukan terhadap limbah cair laboratorium dengan melakukan pengujian konsentarsi COD awal.

Tabel 1 Hasil Pengujian Konsentrasi COD Awal

\begin{tabular}{|c|c|c|c|}
\hline \multirow{2}{*}{ Parameter } & \multicolumn{2}{|c|}{ Konsentrasi COD } & \multirow{2}{*}{ Metode acu } \\
\cline { 2 - 3 } & $\begin{array}{c}\text { sebelum pengujian } \\
(\mathrm{mg} / \mathrm{L})\end{array}$ & $\begin{array}{c}\text { setelah pengujian } \\
(\mathrm{mg} / \mathrm{L})\end{array}$ & \\
\hline COD & \pm 10.000 & $10.090,09$ & SNI 6989.73:2009 \\
\hline
\end{tabular}

Metode pengambilan sampel yang digunakan adalah Grab sample (pengambilan sampel sesaat). Pengambilan sampel air limbah dilakukan pada influent dari Laboratorium. Dari tabel 4.1 limbah cair laboratorium mempunyai konsentrasi COD sebesar 10.090,09 mg/L. Volume sampel yang di ambil yaitu sebanyak 2 liter.

Untuk membuat variasi konsentrasi COD dilakukan pengenceran dari limbah awal agar didapat konsentrasi COD $\pm 5.000 \mathrm{mg} / \mathrm{L}$ dan $\pm 500 \mathrm{mg} / \mathrm{L}$. Limbah diencerkan dengan akuades yang merupakan air bebas mineral.

Dari hasil pengenceran limbah awal, didapat hasil sebagai berikut:

Tabel 2 Hasil Pengujian Konsentrasi COD Setelah Pengenceran

\begin{tabular}{|c|c|c|c|}
\hline \multirow{2}{*}{ Parameter } & \multicolumn{2}{|c|}{ Konsentrasi COD } & \multirow{2}{*}{ Metode acu } \\
\cline { 2 - 3 } & $\begin{array}{c}\text { sebelum pengujian } \\
\text { (mg/L) }\end{array}$ & $\begin{array}{c}\text { setelah pengujian } \\
\text { (mg/L) }\end{array}$ & \\
\hline \multirow{2}{*}{ COD } & \pm 5.000 & 5009,01 & SNI 6989.73:2009 \\
\cline { 2 - 3 } & \pm 500 & 511,71 & SNI 6989.73:2009 \\
\hline
\end{tabular}

Berdasarkan tabel 4.2 konsentrasi COD hasil pengenceran yaitu $5009,21 \mathrm{mg} / \mathrm{L}$ dan $511,71 \mathrm{mg} / \mathrm{L}$.

Konsentrasi COD 511.71. mg/L

Tabel 3 Data Efislenil COD Berdasarkan Perbandingan DoBle

\begin{tabular}{|c|c|c|c|}
\hline $\begin{array}{c}\text { Dosis pereaksi } \\
\text { fenton }\end{array}$ & $\begin{array}{c}\text { Nilai COD } \\
\text { (mg/L) }\end{array}$ & $\begin{array}{c}\text { Efisiensi COD } \\
(\%)\end{array}$ & $\begin{array}{c}\text { Baku Mutu Permen } \\
\text { LH No.5 Tahun } \\
\text { 2014 (mg/L) }\end{array}$ \\
\hline $1: 100$ & 266,67 & 47,89 & \multirow{2}{*}{300} \\
\hline $1: 200$ & 223,42 & 56,34 & \\
\cline { 1 - 2 } $1: 300$ & 86,49 & 83,10 & \\
\hline $1: 400$ & 144,14 & 71,83 & \\
\hline
\end{tabular}

Sumber Dota hasil ansils/s loboretartum, 2016 


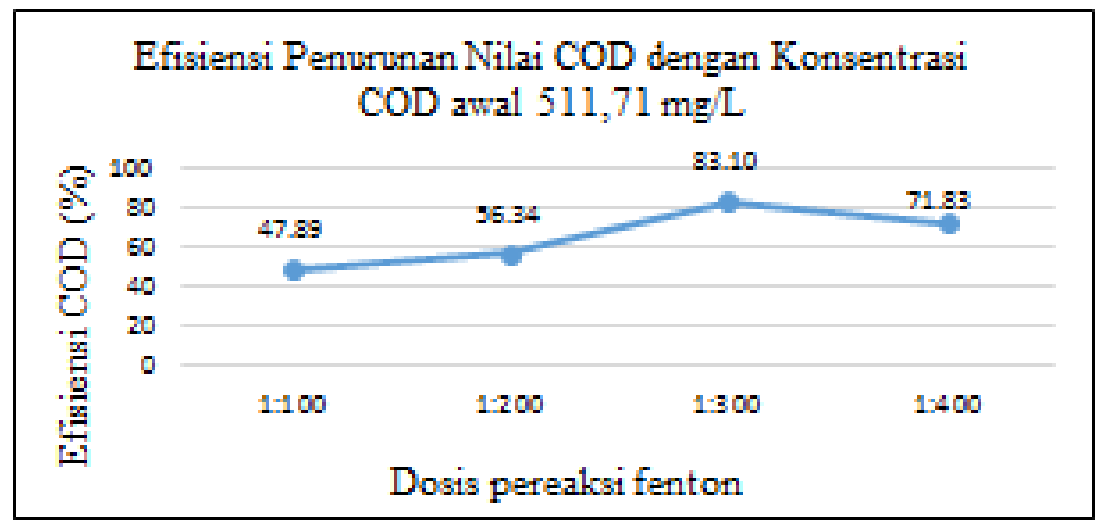

Gambar 2 Graflk eflelenвl penurunan nillal COD dengan koneentrasl COD awal $511,71 \mathrm{mg} / \mathrm{L}$ Sumber: Hasll penellian, 2010

Berdasarkan gambar 2 efisiensi penurunan kadar COD tertinggi yaitu pada dosis pereaksi fenton 1:300 dengan degan nilai efisiensi $83,10 \%$. Sedangkan efisiensi penrunan kadar COD terendah yaitu pada dosis 1:100 dengan nilai efisiensi 47,89\%.

\section{Konsentrasi COD 5009,01 mg/L}

Tabel 4 Data Efisiensi COD Berdasarkan Perbandingan Dosis Pereaksi Fenton Dengan Konsentrasi COD Awal 5.009,01 mg/L

\begin{tabular}{|c|c|c|c|}
\hline $\begin{array}{c}\text { Dosis pereaksi } \\
\text { fenton }\end{array}$ & $\begin{array}{c}\text { Nilai COD } \\
(\mathrm{mg} / \mathrm{L})\end{array}$ & $\begin{array}{c}\text { Efisiensi } \\
\text { COD }(\%)\end{array}$ & $\begin{array}{c}\text { Baku Mutu Permen } \\
\text { LH No.5 Tahun 2014 } \\
(\mathrm{mg} / \mathrm{L})\end{array}$ \\
\hline $1: 100$ & 3279,28 & 34,53 & \multirow{2}{*}{300} \\
\hline $1: 200$ & 3207,21 & 35,97 & \multirow{2}{*}{40,76} \\
\cline { 1 - 2 } $1: 300$ & 2666,67 & 39,57 & \\
\hline 1:400 & 3027,03 & 3016 \\
\hline
\end{tabular}

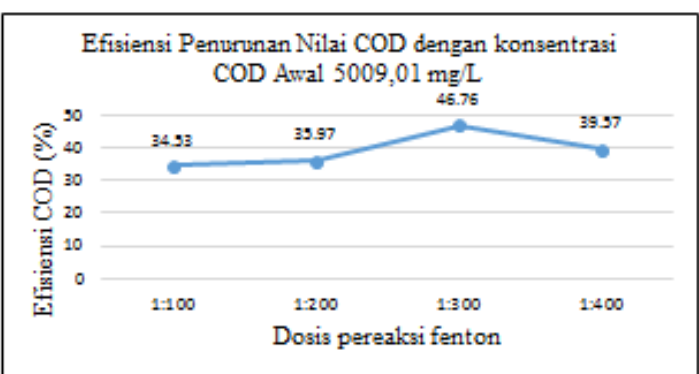

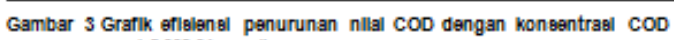
awal $5.009,01 \mathrm{mg} / \mathrm{L}$
Sumber: Hasil penelltan, 2010

Berdasarkan gambar 3 efisiensi penurunan kadar COD tertinggi masih sama dengan penelitian pertama yaitu pada dosis pereaksi fenton 1:300 dengan degan nilai efisiensi $46,76 \%$. Sedangkan efisiensi penrunan kadar COD terendah yaitu pada dosis 1:100 dengan nilai efisiensi 34,53\%.

\section{Konsentrasi COD $10.090,09 \mathrm{mg} / \mathrm{L}$}

Tabel 5 Data Efisiensi COD Berdasarkan Perbandingan Dosis Pereaksi Fenton Dengan Konsentrasi COD Awal $10.090,09 \mathrm{mg} / \mathrm{L}$

\begin{tabular}{|c|c|c|c|}
\hline $\begin{array}{c}\text { Dosis pereaksi } \\
\text { fenton }\end{array}$ & $\begin{array}{c}\text { Nilai COD } \\
(\mathrm{mg} / \mathrm{L})\end{array}$ & $\begin{array}{c}\text { Efisiensi COD } \\
(\%)\end{array}$ & $\begin{array}{c}\text { Baku Mutu } \\
\text { Permen LH No.5 } \\
\text { Tahun 2014 } \\
(\mathrm{mg} / \mathrm{L})\end{array}$ \\
\hline $1: 100$ & 8576,58 & $\mathbf{1 5 , 0 0}$ & \multirow{2}{*}{300} \\
\cline { 1 - 3 } $1: 200$ & 8360,36 & $\mathbf{1 7 , 1 4}$ & \\
\hline $1: 300$ & 7927,93 & $\mathbf{2 1 , 4 3}$ & \\
\hline $1: 400$ & 8144,14 & 19,29 & \\
\hline
\end{tabular}

Sumber Deta hasll anslls/s laboretortum, 2016 

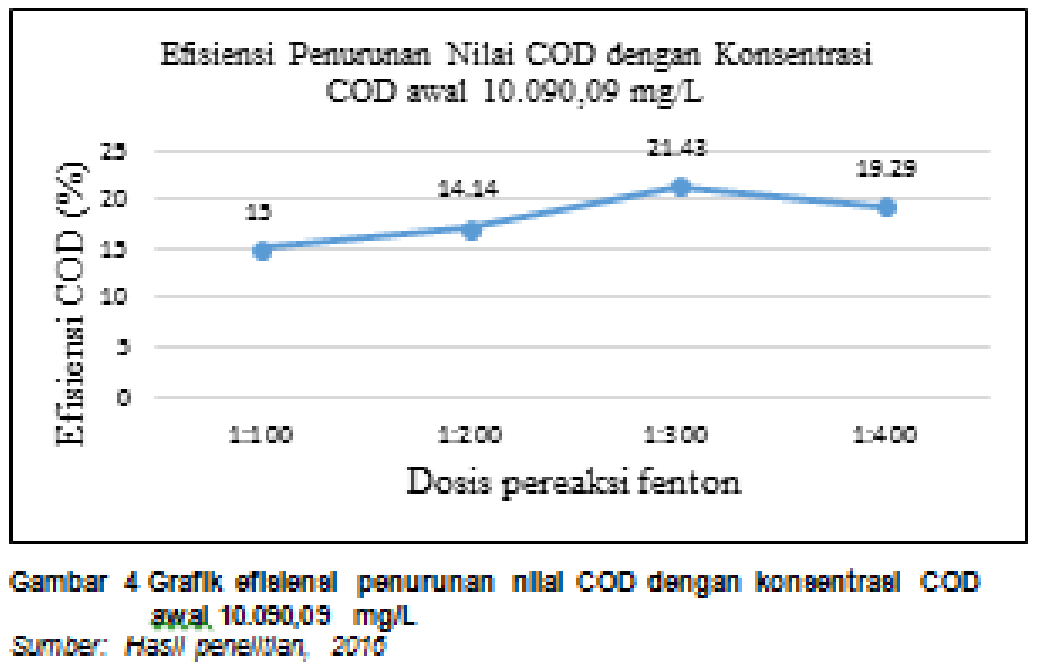

Berdasarkan gambar 4 efisiensi penurunan kadar COD tertinggi yaitu pada dosis pereaksi fenton 1:300 dengan degan nilai efisiensi $21,43 \%$. Sedangkan efisiensi penrunan kadar COD terendah yaitu pada dosis 1:100 dengan nilai efisiensi $15 \%$.

Metode yang diambil untuk penelitian yaitu metode fenton $\left(\mathrm{H}_{2} \mathrm{O}_{2} / \mathrm{Fe}^{2+}\right)$. Hal ini karena metode ini paling mudah untuk dilakukan. Selain itu, limbah laboratorium bersifat asam sehingga tidak memerlukan penambahan asam untuk menyesuaikan $\mathrm{pH}$ limbah.

Dalam penelitian ini, pencampuran $\mathrm{H}_{2} \mathrm{O}_{2}$ dan $\mathrm{FeSO}_{4}$ dilakukan terlebuih dahulu sebelum direaksikan dengan limbah karena agar terbentuk radikal hidroksil sesuai dengan reaksi:

$$
\mathrm{H}_{2} \mathrm{O}_{2}+\mathrm{Fe}^{2+} \rightarrow \mathrm{Fe}^{3+}+\mathrm{OH}^{-}+\mathrm{OH}^{*}
$$

Kondisi $\mathrm{pH}$ optimum pereaksi fenton untuk menurunkan COD terjadi pada $\mathrm{pH}$ 3. Pada $\mathrm{pH}$ ini pembentukan radikal hidroksil maksimum sehingga dapat menurunkan COD yang tertinggi. (Agustina TE, 2012).

Pada $\mathrm{pH}$ dibawah 3 pembentukan radikal hidroksil kurang maksimal karena $\mathrm{pH}$ yang terlalu asam sehingga kemungkinan ion besi kurang maksimal mengkatalisis pembentukan radikal hidroksil, sedangkan pada $\mathrm{pH}$ di atas 3 penurunan COD lebih rendah karena sebagian ion besi mengendap sehingga sebagian hidrogen peroksida tidak stabil dan mengurai menjadi oksigen dan air maka kemampuan oksidasinya berkurang.

Waktu kontak antara pereaksi fenton dengan sampel limbah yaitu 60 menit.(Ramadhan A, 2012). Mekanisme kerja suatu radikal bebas terdiri dari tahap inisiasi ( reaksi saat ikatan terlemah pada reaktan atau salah satu dari reaktan-reaktan putus untuk menghasilkan radikal bebas), tahap propagasi ( radikal bebas menyerang reaktan menghasilkan molekul produk dan spesies reaktif yang lain. Radikal bebas yang baru ini bereaksi lebih lanjut dan membentuk lagi radikal bebas yang semula, yang sekali lagi menyerang reaktan. Dengan jalan ini produk dan pembawa rantai terbentuk secara kontinyu), dan tahap terminasi (reaksi yang mengubah radikal bebas yang stabil dan tidak reaktif sehingga reaksi berakhir).

Hal ini menunjukan tahap radikal hidroksil unuk mengoksidasi zat organic membutuhkan waktu yang cukup lama karena kompleksnya zat organik dalam limbah dan melkanisme reaksi yang bertahap. Waktu kontak dibawah 60 menit mengakibatkan terdapat tahap reaksi yang belum sempurna sehingga penurunan COD kurang maksimal.

Penyaringan dilakukan untuk memisahkan padatan yang tidak terlarut selama proses reaksi antara pereaksi fenton dengan sampel limbah. Hal ini dilakukan karena padatan tersebut tidak akan dibawa ke proses selanjutnya.

Dosis optimum penambahan pereaksi fenton sebesar 1:300. Semakin besar perbandingan nmol pereaksi fenton (dalam hal ini konsentrasi $\mathrm{H}_{2} \mathrm{O}_{2}$ ), maka semakin besar persen efisiensi penurunan COD sampai mencapai keadaan optimum dimana perbandingan mmol pereaksi fenton optimal pada sampel limbah adalah 1:300. Setelah melewati perbandingan mmol pereaksi fenton optimal maka nilai COD akan kembali membesar. Hal ini dikarenakan kenaikan konsentrasi akan menimbulkan konsentrasi $\mathrm{OH}^{*}$ dalam pereaksi, sehingga kemampuan pereaksi fenton untuk 
mengoksidasi kontaminan dari sampel limbah semakin meningkat. Tetapi jika $\mathrm{OH}^{*}$ sudah jenuh untuk mengoksidasi maka pereaksi fenton akan terhitung sebagai polutan sehingga menyebabkan nilai COD menjadi meningkat setelah mencapai kondisi optimum.

Pereaksi fenton terlihat sangat efisien pada kadar COD yang rendah yaitu 511,17 mg/L. Efisiensi yang didapat mencapai $83,10 \%$. Hal ini berbanding terbalik dengan kadar COD yang tinggi yaitu $10.090,09 \mathrm{mg} / \mathrm{L}$ dengan efisiensi penurunannya hanya $21,43 \%$. Hal ini disebabkan pada konsentrasi COD $511,17 \mathrm{mg} / \mathrm{L}$ ringannya beban COD yang diolah. Sedangkan pada konsentrasi COD 10.090,09 mg/L banyaknya senyawa organik sehingga membuat beban semakin berat untuk diolah oleh radikal hidroksil pereaksi fenton.

\section{KESIMPULAN}

Berdasarkan hasil penelitian,maka dosis optimum dari pereaksi fenton adalah 1:300 dengan efisiensi penurunan kadar COD dengan data sebagai berikut.

1. Pada kadar COD $511,71 \mathrm{mg} / \mathrm{L}$ penurunan kadar COD optimum sebesar $83,10 \%$. Hal ini dipengaruhi oleh kecilnya nilai COD pada sampel air limbah sehingga beban pereaksi fenton tidak terlalu berat.

2. Pada kadar COD 5009,01 mg/L penurunan kadar COD optimum sebesar 46,76\%. Penurunan persen efisiensi sudah berkurang dari kadar $511,17 \mathrm{mg} / \mathrm{L}$ hal ini dipengaruhi oleh beban pereaksi fenton yang semakin berat.

3. Pada kadar COD 10.090,09 mg/L penurunan kadar COD optimum sebesar 21,43\%. Penurunan nilai COD pada kadar 10.090,09 mg/L semakin mengecil. Hal ini dipengaruhi oleh tingginya kadar awal COD pada sampel.

Pereaksi fenton sangat efektif digunakan untuk mengolah limbah dengan kisaran konsentrasi COD $500 \mathrm{mg} / \mathrm{L}$ dengan rasio dosis 1:300 mmol.

\section{DAFTAR PUSTAKA}

Elfiana, 2013, "Kajian Efektifitas Reagen Fenton Untuk Menurunkan Konsentrasi COD Air Limbah Domestik Secara Batch Pada Metode AOP". Teknik Kimia Politeknik Negeri Lhoksmawe.

Agustina, T.E. 2012. "Penggunaan Reagen Fenton dan Adsorpsi Terhadap Penurunan Kadar COD Pada Air Limbah Pencucian Biji Kopi”. Fakultas Teknik Universitas Sriwijaya.

Filipek, K, Barbusinki, K. 2003. Aerobic Sludge Digestion in the Presence of Hydrogen Peroxide and Fenton's Reagent. Polish Journal of Environmental Studies, Vol. 12, No. 1, pp.35-40.

Hutagalung, S. 2015. "Metode Advance Oxidation Processes (AOPs) untuk mengolah limbah resin". Pusat Penelitian Ilmu pengetahuan dan Teknologi-RISTEK. ISSN 1410-6086.

Ramadhan, A. 2012. "Membandingkan Pereaksi Fenton dan Kaporit Dalam Menurunkan Chemical Oxygen Demand (COD) Limbah Larutan Penyapu Jenuh". Fakultas MIPA Universitas Pakuan Bogor.

Sholeh, M., Supraptiningsih, dan Arsitika,W. 2013. "Penurunan COD Air Limbah Industri Penyamakan Kulit Menggunakan Reagen Fenton”. Majalah Kulit, Karet dan Plastik, 29(1):31-36.

Standar Nasional Indonesia 6689.73:2009, air dan air limbah-bagian 73: Cara Uji Kebutuhan Oksigen KImiawi (Chemical Oxygen Demand/COD) dengan refluks tertutup secara titrimetri.

Sugiharto. 1987. “Dasar-Dasar Pengolahan Air Limbah”. UI Press. Jakarta.

Eckenfelder, W, Jr. 1989. "Industrial Water Pollution Control Second Edition”. Mc. Graw Hill. Singapore. 